\title{
Xác định hàm lượng Icariin trong thực phẩm bảo vệ sức khỏe bằng kĩ thuật sắc kỹ lởng hiệu năng cao
}

\author{
Vũ Thị Thanh An ${ }^{2^{*}}$, Lương Thế Dũng ${ }^{1}$ Mạc Thị Thanh Hoa², Cao Công Khánh ${ }^{2}$ \\ ${ }^{1}$ Trường Đại học Khoa học Tự nhiên, Đại học quốc gia Hà Nội \\ ${ }^{2}$ Viện Kiểm nghiệm an toàn vệ sinh thực phẩm Quốc gia
}

(Ngày đến tòa soạn: 03/6/2020; Ngày chấp nhận đăng: 30/6/2020)

\section{Tóm tắt}

Kỹ thuật sắc ký lỏng hiệu năng cao kết hợp với detector PDA đã được ứng dụng phân tích hàm lượng Icariin trong thực phẩm bảo vệ sức khỏe (TPBVSK) có chứa thành phân Dâm dương hoắc (Epimedium). Giai đoạn xử lý mẫu sử dụng dung môi chiết methanol và kỹ thuật siêu âm cách thủy. Quy trình phân tích được thực hiện trên hệ thống HPLC Alliance-Waters e2695 với cột sắc ký pha đảo C18 Reliant $2(250 \mathrm{~mm} \times 4,6 \mathrm{~mm}, 5 \mu \mathrm{m})$ và pha động theo gradient giữa acetonitril với dung dịch acid phosphoric $1 \%$ trong 20 phút. Kết quả thẩm định cho thấy phương pháp có độ đặc hiệu tốt, đường chuẩn tuyến tính trong khoảng từ $0,42-42 \mu \mathrm{g} / \mathrm{mL}$, độ lặp lại và độ thu hôi của phương pháp đáp ứng được yêu câu phân tích theo AOAC. Phương pháp đã được triển khai phân tích một số sản phẩm TPBVSK và nguyên liệu cao khô Dâm dương hoắc có mặt trên thị trường với kết quả hàm lượng Icariin từ 6,15 - 54,3 mg/g (đối với sản phẩm TPBVSK) và từ 6,47 - 24,5 g/100g (đối với mẫu nguyên liệu cao khô).

Từ khóa: Icariin, dâm dương hoắc, HPLC, thực phâm bảo vệ sức khỏe, TPBVSK.

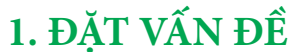

Tại Việt Nam, các sản phẩm thực phẩm bảo vệ sức khỏe (TPBVSK) có nguôn gốc từ các bài thuốc cổ truyền với thành phẩn chính là các dược liệu đang được phát triển đa dạng. Trong số các dược liệu đó, Dâm dương hoắc (Epimedium) - một loại dược liệu thường được sử dụng trong các bài thuốc cổ truyền với tác dụng chữa các bệnh về thận, liệt dương, đau nhức xương khớp [1]. Nhu câuu sử dụng các sản phẩm TPBVSK trong hỗ trợ điều trị và phòng ngừa bệnh tật, nâng cao sức khỏe của người dân đang được nâng cao. Chính vì thế trên thị trường hiện tại đã xuất hiện rất nhiều các sản phẩm thực phẩm bảo vệ sức khỏe có công bố thành phần Dâm dương hoắc.

Với sự phát triển của khoa học kỹ thuật, các nhà khoa học đã phát hiện ra thành phân chính có tác dụng của Dâm dương hoắc cũng như các dược liệu chi Dâm dương hoắc (Epimedium) là Icariin. Icariin có bản chất là flavonol có khung cấu trúc tương tự kaempferol đã được thay thế ở vị trí 08 bởi nhóm 3-methylbut-2-en-1-yl và trong đó các nhóm hydroxy ở vị trí 03, 04 và 07 đã được chuyển đổi tương ứng với 6-deoxy-alpha-L-mannopyranoside, methyl ether và betaD-glucopyranoside [3].

Sau khi được hấp thu vào cơ thể, Icariin được phân bố và có thể đi tới nhiều vị trí trong cơ thể, bao gồm cả não bộ. Do đó, Icariin thể hiện một số hoạt động sinh học như tác dụng chống 
oxy hóa và chống viêm, bảo vệ thần kinh, hoạt động chống khối u, cũng như tác động khác lên tim, xương, ức chế PDE5 và nhiều cơ quan khác [5].

Hiện nay, đối với các mặt hàng thực phẩm bảo vệ sức khỏe, nước ta có rất ít các phương pháp tiêu chuẩn để phân tích hàm lượng các thành phần, đặc biệt là các hoạt chất có nguôn gốc từ dược liệu. Chính vì thế thực tế đặt ra yêu cầu cần phải có nhiều hơn nữa các phương pháp kiểm nghiệm các thành phần trong thực phẩm bảo vệ sức khỏe nói chung và phân tích Icariin nói riêng nhằm góp phần bảo vệ quyền lợi người tiêu dùng cũng như hỗ trợ các cơ quan chức năng trong việc kiểm soát tốt hơn vấn đề chất lượng sản phẩm. Trên thế giới hiện nay đã phát triển một số phương pháp xác định hàm lượng Icariin trên nhiều nền mẫu khác nhau như điện di (CE), sắc ký lớp mỏng hiệu năng cao (HPTLC), sắc ký lỏng hiệu năng cao (HPLC), sắc ký lỏng khối phổ (LC-MS/MS) [3-5], trong đó HPLC phương pháp có độ nhạy tốt, phổ biến và dễ áp dụng trên phạm vi rộng.

\section{VẠT LIỆU VÀ PHƯƠNG PHÁP NGHIÊN CƯU}

\section{1. Đối tượng nghiên cứu}

Nghiên cứu này tập trung phân tích hàm lượng Icariin trong các sản phẩm TPBSVK dạng viên nén, viên nang, dạng lỏng và dạng nguyên liệu cao Dâm dương hoắc.

\subsection{Hóa chất, chất chuẩn}

\subsubsection{Thiết bị, dụng cu}

Các loại thiết bị, dụng cụ chính được sử dụng trong nghiên cứu này gồm có:

- Thiết bị sắc ký lỏng hiệu năng cao HPLC Allience với detector PDA;

- Cột sắc ký C18 (250 mm × 4,6 mm; $5 \mu \mathrm{m})$ và tiền cột tương ứng;

- Các dụng cụ và thiết bị phụ trợ khác trong phòng thí nghiệm.

\subsubsection{Hóa chất, chất chuân}

Các loại dung môi, hóa chất được sử dụng là loại tinh khiết phân tích, dùng cho sắc ký lỏng hiệu năng cao hoặc có chất lượng tương đương.

- Chất chuẩn Icariin, độ tinh khiết 98\%, Lot PRF9031903 (Biopurify);

- Acetonitril, acid phosphoric, methanol, ethanol (Merck), nước đề ion.

\subsection{Phương pháp nghiên cứu}

\subsubsection{Phương pháp lấy mẫu}

Các mẫu TPBVSK được lấy ngẫu nhiên trên thị trường Hà Nội. Được bảo quản theo đúng yêu cầu của nhà sản xuất trong quá trình phân tích

\subsubsection{Phương pháp phân tích}

- Thử nghiệm và lựa chọn các thông số của hệ thống HPLC khi phân tích Icariin cho pic sắc ký có tín hiệu ổn định, cân xứng và tách hoàn toàn với các pic tạp khác: cột sắc ký, pha động (thành phần và gradient), bước sóng định lượng, ...

- Thử nghiệm và lựa chọn quá trình xử lý mẫu: dung môi chiết, số lần chiết, kỹ thuật chiết để đảm bảo chiết chất phân tích đạt hiệu quả cao, đơn giản, dễ thực hiện. 
- Thẩm định phương pháp theo hướng dẫn của tài liệu tham khảo [2].

\subsubsection{Xử lý sốliệu}

- Phần mềm Empower của hệ thống HPLC;

- Phần mềm Microsoft Excel;

- Một số công thức thống kê thường dùng trong phân tích.

\section{KẾT QUẢ VÀ BÀN LUẬN}

\subsection{Nghiên cứu xây dựng phương pháp phân tích}

\subsubsection{Khảo sát và lựa chọn điêu kiện sắc ký}

Qua tham khảo các tài liệu tham khảo [3-5], kết hợp với việc tiến hành khảo sát thực tế trên thiết bị HPLC Alliance -Waters e2965, điều kiện phân tích Icariin trong nền mẫu thực phẩm bảo vệ sức khỏe như sau:

- Cột Reliant C18 (250 mm × 4,6 mm, $5 \mu \mathrm{m}$ ) và tiền cột tương ứng;

- Pha động: theo chương trình Gradient tại Bảng 1;

- Tốc độ dòng: 1,0 mL/min; Thể tích mẫu: $20 \mu \mathrm{L}$;

- Bước sóng phát hiện và định lượng: $260 \mathrm{~nm}$, khoảng ghi phổ: 200 - 600 nm.

Hình 1 là sắc ký đồ phân tích dung dịch chuẩn Icariin với các thông số trên.

Bảng 1. Chương trình gradient pha động phân tích Icariin

\begin{tabular}{ccc}
\hline Thòi gian (min) & $\mathbf{H}_{\mathbf{3}} \mathbf{P O}_{\mathbf{4}} \mathbf{1 \%} /$ nước (\%) & Acetonitril (\%) \\
\hline 0,0 & 90 & 10 \\
1,0 & 90 & 10 \\
3,0 & 50 & 50 \\
5,0 & 30 & 70 \\
13 & 30 & 70 \\
15 & 90 & 10 \\
20 & 90 & 10 \\
\hline
\end{tabular}

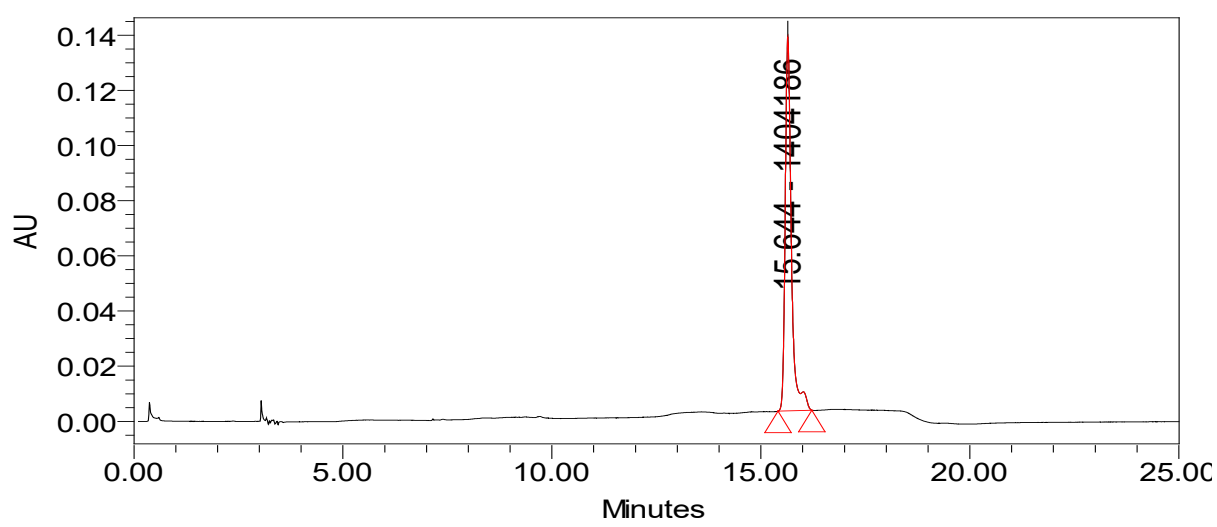

Hình 1. Sắc ký đồ phân tích Icariin bằng HPLC 
Với thời gian lưu của Icariin khoảng 15,6 phút sẽ đảm bảo khả năng tách chất phân tích với tạp chất khác trong nền mẫu và giúp ổn định về thời gian lưu, tín hiệu đáp ứng giữa các lân thừ.

\subsubsection{Khảo sát và lựa chọn điều kiện xủ lý mẫu}

Icariin là chất có độ tan tốt trong nước và các alcol. Trong các nghiên cứu chiết xuất Icariin từ dược liệu Dâm dương hoắc, phương pháp chiết thường được sử dụng là chiết hôii lưu với ethanol hoặc methanol. Khi được bổ sung vào nển mẫu thực phẩm chức năng, dù là ở dạng hoạt chất hay trong dược liệu, cao dược liệu, việc chiết tách Icariin vẫn bị ảnh hưởng bởi các tá dược cũng như các thành phần hoạt chất khác có trong nền mẫu. Chính vì thế, nghiên cứu đã tiến hành khảo sát trên 02 dung môi alcol chính là ethanol và methanol với các nồng độ khác nhau cũng như thời gian chiết khác nhau để lựa chọn điều kiện tối ưu chiết tách Icariin ra khỏi nền mẫu với hiệu suất cao nhất.

\subsubsection{Khảo sát dung môi chiết mẫu}

Thử nghiệm 05 loại dung môi: ethanol 50\%, ethanol 100\%, methanol 50\%, methanol 70\%, methanol $100 \%$ đã được khảo sát bằng cách cân cùng khoảng 1,0 g mẫu TPBVSK dạng viên nang cứng đã đồng nhất, chiết với $20 \mathrm{~mL}$ dung môi trong 15 phút với sự hỗ trợ của bể siêu âm cách thủy, sau đó so sánh hàm lượng Icariin chiết được để đánh giá hiệu suất chiết. Kết quả về hiệu quả chiết của các loại dung môi được thể hiện trong Hình 2.

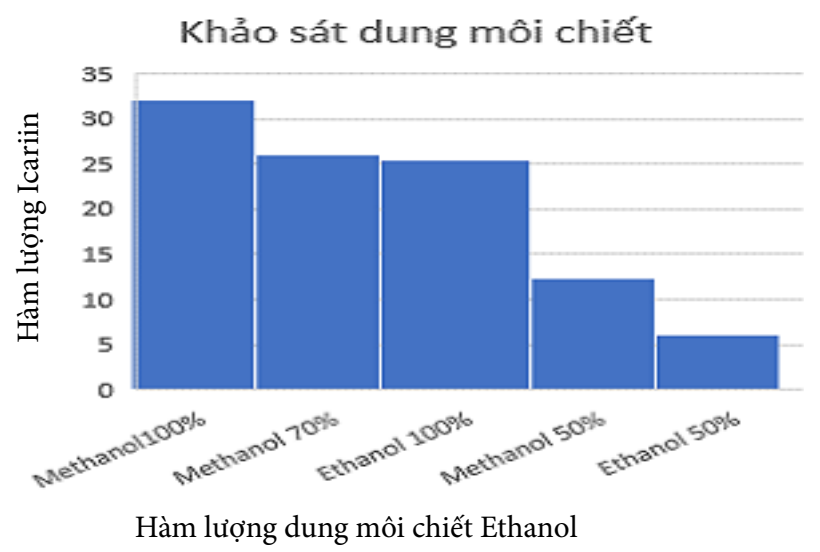

Hình 2. Biêu đồ thể hiện hiệu quả chiết của các loại dung môi

Kết quả cho thấy, dung môi methanol 100\% cho hàm lượng Icariin chiết ra lớn nhất trong 05 hệ dung môi đã khảo sát. Do vậy methanol được lựa chọn làm dung môi chiết mẫu.

\subsubsection{Khảo sát số lần chiết mẫu}

Để khảo sát số lần chiết mẫu, 01 mẫu TPBVSK dạng viên nang cứng chứa Icariin được cân khoảng 1,0 g, chiết bằng methanol 05 lân (mỗi lần $20 \mathrm{~mL}$ ) sử dụng kỹ thuật siêu âm cách thủy 15 phút, sau đó được phân tích theo điều kiện đã lựa chọn ở trên (3.1.1). Kết quả xác định số lần chiết tối ưu dựa trên phần trăm mẫu chiết giữa các lần cho thấy sau lần chiết thứ 02 , lượng Icariin có trong nền mẫu gần như đã được chiết hết, các lần chiết tiếp theo hầu như không còn lượng Icariin đáng kể. Do đó, quy trình chiết Icariin trong các mẫu TPBVSK sử dụng 02 lân chiết. Kết quả phân tích hàm lượng Icariin trong nền mẫu TPBVSK dạng viên nang cứng được thể hiện trong Hình 3. 


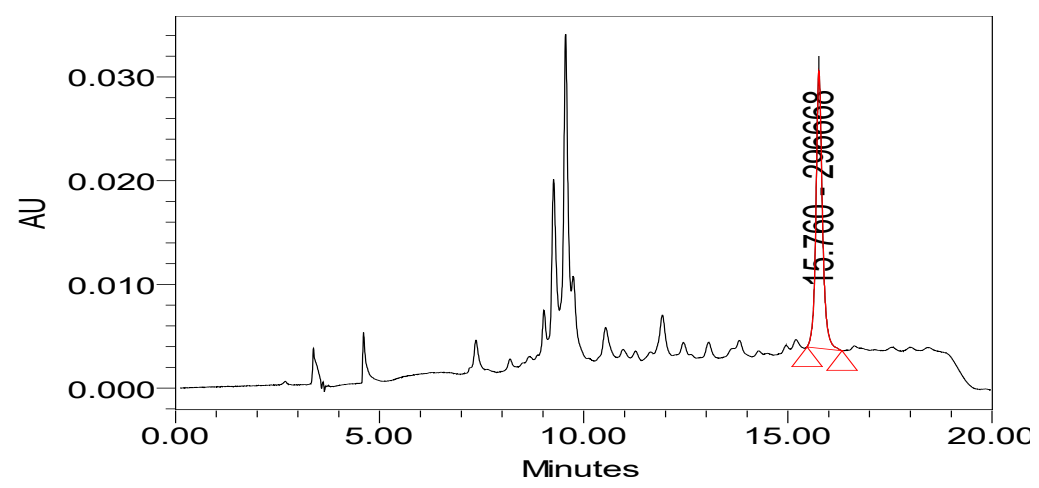

Hình 3. Sắc ký đồ phân tích Icariin trong mẫu TPBVSK dạng viên nang cứng

\subsubsection{Khảo sát kỹ thuật chiết mẫu}

Để khảo sát kỹ thuật chiết mẫu sử dụng mẫu TPBVSK dạng viên nang cứng, lần lượt thử nghiệm sử dụng kỹ thuật siêu âm cách thủy 15 phút, 30 phút, kỹ thuật lắc ngang 15 phút, 30 phút và kỹ thuật ngâm 15 phút, 30 phút (thỉnh thoảng lắc đều) sử dụng dung môi chiết là methanol (chiết 02 lần $\times 20 \mathrm{~mL} /$ ần, định mức $50 \mathrm{~mL}$ bằng methanol và phân tích trên hệ thống $\mathrm{HPLC}$ ). Kết quả phân tích hàm lượng Icariin trong nền mẫu TPBVSK dạng viên nén được thể hiện trong Bảng 2.

Bảng 2. Kết quả thử nghiệm kỹ thuật chiết

\begin{tabular}{cc}
\hline Kỹ thuật chiết & Hàm lự̛ng Icariin $(\boldsymbol{m g} / \mathbf{g})$ \\
\hline Siêu âm 15 phút & 25,7 \\
Siêu âm 30 phút & 25,9 \\
Lắc ngang 15 phút & 20,4 \\
Lắc ngang 30 phút & 21,1 \\
Ngâm 15 phút & 17,5 \\
Ngâm 30 phút & 19,2 \\
\hline
\end{tabular}

Kết quả từ Bảng 2 cho thấy, kỹ thuật chiết siêu âm cho hiệu quả cao nhất và sự khác biệt giữa thời gian chiết 15 phút và 30 phút là không đáng kể.

Như vậy, sau quá trình khảo sát, quy trình chiết Icariin trong các mẫu TPBVSK như sau:

Cân chính xác $1 \mathrm{~g}$ mẫu đã đồng nhất, chiết lặp lại 02 lần với $20 \mathrm{~mL}$ methanol/lần, siêu âm cách thủy 15 phút/lần. Dịch chiết được gộp lại và định mức $50 \mathrm{~mL}$ bằng methanol, sau đó lọc, pha loãng (nếu cần) và phân tích trên hệ thống HPLC.

\subsection{Xác định giá trị sử dụng của phương pháp phân tích}

Phương pháp được lựa chọn dựa trên việc khảo sát điều kiện phân tích và xử lý mẫu, tiếp tục được xác nhận giá trị sử dụng theo các yêu cầu về thẩm định phương pháp hóa học [2]. Kết quả được thể hiện như sau:

\subsection{1. Độ đặc hiệu}

Sắc ký đồ của mẫu trắng, tại thời gian lưu của Icariin không có peak, thời gian lưu giữa mẫu chuẩn và mẫu thêm chuẩn giống nhau (Hình $4 \mathrm{a})$. 
Phổ hấp thụ UV của peak Icariin trong sắc ký đô mẫu chuẩn và mẫu thêm chuẩn trùng khớp nhau (Hình 4b).
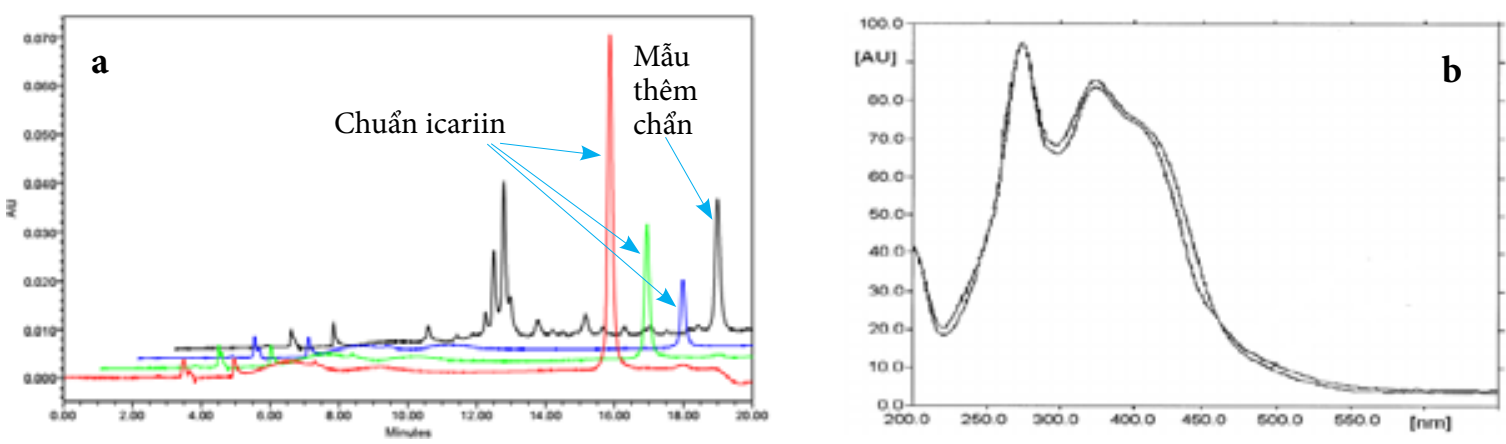

Hình 4. Kết quả chồng píc sắc ký của chuân icariin và mẫu thêm chuẩn (a) và phổ UV-VIS của Icariin trong sắc ký đồ mẫu chuân và mẫu thêm chuân (b)

\subsubsection{Khoảng tuyến tính}

Phân tích dãy các dung dịch chuẩn Icariin với các nồng độ khác nhau trên hệ thống HPLC với các điều kiện đã được lựa chọn ở trên. Kết quả tại Bảng 3 cho thấy khoảng tuyến tính từ $0,42-42,0 \mu \mathrm{g} / \mathrm{mL}$.

Bảng 3. Đường chuân và khoảng tuyến tính của Icariin

\begin{tabular}{cccc}
\hline Nồng độ $(\boldsymbol{\mu g} / \mathbf{m L})$ & Diện tích pic & $\boldsymbol{C} \boldsymbol{t t}(\boldsymbol{\mu} \mathbf{g} \mathbf{m L})$ & Bias $(\%)$ \\
\hline 2,0 & 1517101 & 42,02 & 0,0 \\
21,0 & 752350 & 20,95 & 0,0 \\
8,40 & 292974 & 8,30 & $-1,2$ \\
4,20 & 142201 & 4,15 & $-1,3$ \\
2,10 & 69803 & 2,15 & 2,7 \\
0,84 & 23717 & 0,88 & 5,2 \\
0,42 & 8136 & 0,45 & 7,9 \\
\hline
\end{tabular}

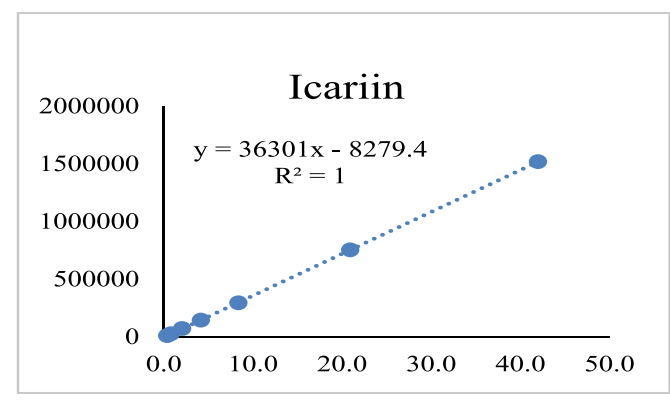

Hình 5. Đường chuân Icariin

Với khoảng tuyến tính rộng như trên, phương pháp có thể thực hiện phân tích hàm lượng Icariin trong các loại mẫu TPBVSK với các mức khác nhau.

3.2.3. Giới hạn phát hiện (LOD), giới hạn định lượng (LOQ)

Thực hiện phân tích các mẫu trắng thêm chuẩn có nồng độ thấp, xác định $L O D$ và $L O Q$ tại điểm nồng độ thêm chuẩn lần lượt cho tín hiệu $\mathrm{S} / \mathrm{N}=3$ và $\mathrm{S} / \mathrm{N}=10$, kết quả thu được: 
- Nền TPBVSK dạng lỏng: LOD = 13,5 $\mu \mathrm{g} / \mathrm{g}$; LOQ = 45,0 $\mu \mathrm{g} / \mathrm{g}$

- Nền TPBVSK dạng rắn: $\mathrm{LOD}=9,62 \mu \mathrm{g} / \mathrm{g} ; \mathrm{LOQ}=32,0 \mu \mathrm{g} / \mathrm{g}$

Với các giá trị $L O D$ và $L O Q$ trên, phương pháp có thể đáp ứng yêu câu phân tích của các mẫu TPBVSK có bổ sung thành phân Dâm dương hoắc.

\subsection{4. Độ lặp lại}

Thực hiện xác định độ lặp lại của phương pháp trên nền mẫu TPBVSK dạng lỏng và dạng rắn chứa thành phần Dâm dương hoắc. Mỗi nền mẫu phân tích 06 lần, kết quả thu được tại Bảng 4 .

Bảng 4. Kết quả phân tích độ lặp lại

\begin{tabular}{ccccc}
\hline Nền mẫu & Hàm lượng & \multicolumn{2}{c}{ Mức yêu cầu AOAC } & Kết quả \\
\hline Dạng lỏng & $1,65 \mathrm{~g} / 100 \mathrm{~g}$ & Hàm lượng 1\% & $\mathrm{RSD}_{\mathrm{r}} \leq 2,7 \%$ & 2,09 \\
Dạng rắn & $9,81 \mathrm{~g} / 100 \mathrm{~g}$ & Hàm lượng 10\% & $\mathrm{RSD}_{\mathrm{r}} \leq 1,8 \%$ & 1,59 \\
\hline
\end{tabular}

Các kết quả tại Bảng 4 cho thấy phương pháp đạt yêu cầu của AOAC [2] về độ lặp lại đối với hai nền mẫu có hàm lượng khác nhau.

\subsection{5. Độ tái lập trung gian}

Thực hiện như độ lặp lại nhưng với người và thời gian phân tích khác. Kết quả thu được tại Bảng 5 .

Bảng 5. Kết quả phân tích độ tái lập trung gian

\begin{tabular}{ccccc}
\hline Nền mẫu & Hàm lượng & \multicolumn{2}{c}{ Mức yêu cầu AOAC } & Kết quả \\
\hline Dạng lỏng & $1,58 \mathrm{~g} / 100 \mathrm{~g}$ & Hàm lượng 1\% & $\mathrm{RSD}_{\mathrm{R}} \leq 4,0 \%$ & 3,21 \\
Dạng rắn & $9,74 \mathrm{~g} / 100 \mathrm{~g}$ & Hàm lượng 10\% & $\mathrm{RSD}_{\mathrm{R}} \leq 3,0 \%$ & 2,17 \\
\hline
\end{tabular}

Các kết quả tại Bảng 5 cho thấy phương pháp đạt yêu cầu của $\mathrm{AOAC}$ [2] vê độ tái lập trung gian đối với hai nền mẫu có hàm lượng khác nhau.

\subsection{6. Độ thu hôi}

Thực hiện thêm lượng chuẩn Icariin xác định vào các mẫu trắng, mỗi nền mẫu thực hiện 06 lần rồi phân tích theo quy trình đã xác định ở trên. Dựa trên mức hàm lượng thực tế phân tích được, tính độ thu hôi. Kết quả thu được tại Bảng 6 .

Bảng 6. Kết quả phân tích độ thu hôi

\begin{tabular}{cccc}
\hline Nền mẫu & Thêm chuẩn & Độ thu hôi (\%) & Múc yêu cầu \\
\hline Dạng lỏng & $0,01 \%$ & $95,6-103,9 \%$ & $90-107 \%$ \\
Dạng rắn & $0,1 \%$ & $96,8-102,3 \%$ & $95-105 \%$ \\
\hline
\end{tabular}

Từ các kết quả thu được ở trên cho thấy phương pháp đạt yêu cầu của AOAC [2] về độ thu hôi đối với hai nền mẫu có mức thêm chuẩn hàm lượng khác nhau. 


\subsection{Kết quả xác định hàm lượng Icariin trong các mẫu thực}

Ửng dụng phương pháp đã xây dựng để kiểm nghiệm các mẫu TPBVSK và một số nguyên liệu cao khô Dâm dương hoắc được lấy ngẫu nhiên trên thị trường, tập trung chủ yếu vào các sản phẩm có tác dụng cải thiện tăng cường sinh lý, hỗ trợ điều trị rối loạn nội tiết. Kết quả thu được tại Bảng 7 và Hình 5.

Bảng 7. Kết quả phân tích một số mẫu thực tế

\begin{tabular}{|c|c|c|c|c|c|}
\hline Mẫu & Nền mẫu & $\begin{array}{l}\text { Hàm lượng } \\
\quad(m g / g)^{(*)}\end{array}$ & $M \tilde{a} u$ & Nền mẫu & $\begin{array}{l}\text { Hàm lượng } \\
(m g / g)^{(*)}\end{array}$ \\
\hline M1 & Viên nén & $26,0 \pm 1,2$ & M7 & Viên nang mềm & $6,15 \pm 0,4$ \\
\hline M2 & Viên nén & $14,1 \pm 0,7$ & M8 & Viên nang mềm & $24,1 \pm 1,1$ \\
\hline M3 & Viên nén & $54,3 \pm 2,1$ & M9 & Dạng dung dịch & $16,0 \pm 0,7$ \\
\hline M4 & Viên nang cứng & $35,7 \pm 1,8$ & M10 & Cao khô & $245 \pm 15$ \\
\hline M5 & Viên nang cứng & $2,04 \pm 0,2$ & M11 & Cao khô & $98,5 \pm 4,6$ \\
\hline M6 & Viên nang cứng & $18,6 \pm 0,8$ & M12 & Cao khô & $64,7 \pm 3,2$ \\
\hline
\end{tabular}

Ghi chú: $\left(^{*}\right)$ Hàm lượng Icariin trong các mẫu thực được tính theo dạng nguyên trạng.
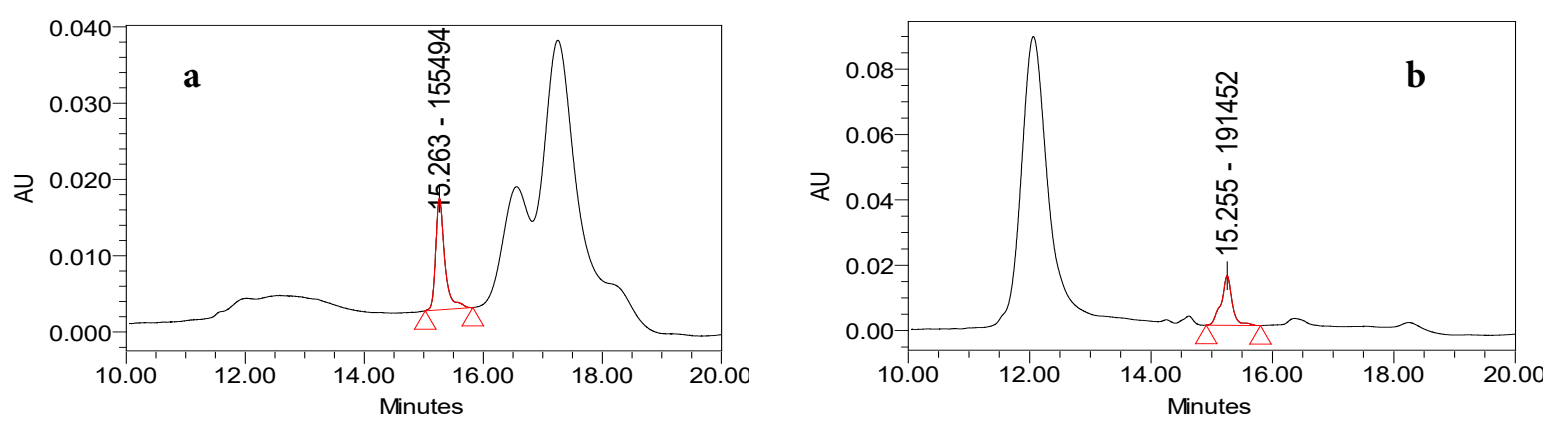

Hình 6. Sắc ký đồ phân tích mẫu TPBVSK dạng viên nang mềm (a) và dạng lỏng (b)

Từ kết quả trên cho thấy, hàm lượng Icariin có trong các thực phẩm bảo vệ sức khỏe dạng viên nén từ $14,1-54,3 \mathrm{mg} / \mathrm{g}$, dạng viên nang cứng từ $2,04-35,7 \mathrm{mg} / \mathrm{g}$, dạng viên nang mêm từ $6,15-24,1 \mathrm{mg} / \mathrm{g}$. Hơn nữa, qua phân tích sơ bộ cho thấy hàm lượng Icariin trong một số mẫu nguyên liệu cao khô Dâm dương hoắc lấy ngẫu nhiên trên thị trường cũng rất khác nhau $(6,47$ - 24,5\%). Tuy nhiên, đây mới chỉ là các kết quả sơ bộ ban đầu, để có đánh giá đây đủ hơn về các mức hàm lượng Icariin trong các mẫu TPBVSK và các mẫu nguyên liệu cao Dâm dương hoắc trên thị trường, cần tiến hành phân tích tiếp tục với số lượng mẫu lớn hơn.

Các kết quả phân tích các mẫu thực cho thấy phương pháp có độ chính xác, độ tin cậy và có tính khả thi cao, có thể triển khai áp dụng tại các phòng thí nghiệm an toàn thực phẩm để kiểm nghiệm, đánh giá chất lượng các sản phẩm TPBVSK chứa thành phân Dâm dương hoắc.

\section{KẾT LUẬN}

Nghiên cứu đã xây dựng được quy trình phân tích Icariin trong các mẫu TPBVSK bằng phương pháp HPLC-DAD. Quy trình xử lý mẫu đơn giản bằng cách chiết 02 lần trong methanol với sự hỗ trợ của siêu âm cách thủy 15 phút. Thời gian phân tích trên HPLC trong 20 phút với cột sắc ký $\mathrm{C} 18$ và pha động gradient của acetonitrile với dung dịch acid phosphoric $1 \%$. Kết quả thẩm định cho thấy, phương pháp có độ đặc hiệu cao, giá trị giới hạn định lượng nhỏ $(0,45 \mu \mathrm{g} / \mathrm{g}$ 
đối với dạng lỏng, $0,32 \mu \mathrm{g} / \mathrm{g}$ đối với dạng rắn); khoảng tuyến tính rộng (từ $0,42-42 \mu \mathrm{g} / \mathrm{mL}$ ); độ thu hôi, độ lặp lại, độ tái lập trung gian đáp ứng yêu câu đối với phương pháp phân tích theo AOAC. Phương pháp đã được ứng dụng phân tích các mẫu TPBVSK chứa Dâm dương hoắc cho thấy hàm lượng Icariin có trong không đông đều cả ở trong cùng dạng bào chế và giữa các dạng bào chế khác nhau.

\title{
TÀI LIẸU THAM KHẢO
}

[1]. Đỗ Tất Lợi, Nhũng cây thuốc và vị thuốc Việt Nam, Hà Nội: Nhà xuất bản Y học, 2006.

[2]. Viện Kiểm nghiệm an toàn vệ sinh thực phẩm Quốc gia, Thẩm định phuiơng pháp trong phân tích hóa học và vi sinh vật, Hà Nội: Nhà xuất bản Khoa học Kỹ thuật, 2010.

[3]. Z. Yang, J. Zhao, "Qualitative and quantitative analysis of icariin analogues in Epimedium koreanum by UPLC-Q-TOF-MS", Journal of Chinese Mass Spectrometry Society, vol.38, no.1, pp. 19-29, 2017.

[4]. O. N. Pozharitskaya, V. M. Kosman, A. N. Shikov. D. Demchenko, "Comparison between HPLC and HPTLC densitometry for the determination of icariin from Epimedium koreanum extracts", Journal of Separation Science, vol. 30, no. 5, pp. 708-712, 2007.

[5]. Y. Chai, S. Ji, Zhang Guoqing, Y. Wu, X. Yin, "Determination of icariin in Chinese traditional medicine by capillary zone electrophoresis", Biomedical Chromatography, vol. 13, no. 5, pp. 373-375, 1999.

\section{Determination of Icariin content in dietary supplements by high performance liquid chromatography}

\author{
Vu Thi Thanh An', Luong The Dung', Mac Thi Thanh Hoa ${ }^{2}$, Cao Cong Khanh ${ }^{2}$ \\ ${ }^{1}$ University of Science, Vietnam National University, Hanoi \\ ${ }^{2}$ National Institute for Food Control, Hanoi
}

\section{Abstract}

High performance liquid chromatography with PDA detector technique has been applied to analyze the Icariin content in dietary supplements that contains the ingredient of Epimedium. Sample preparation used methanol solvent and ultrasonic technique. Analytical procedure performed on HPLC Alliance-Waters e2695 system with chromatographic column C18 Reliant $2(250 \mathrm{~mm} \times 4.6 \mathrm{~mm}, 5 \mu \mathrm{m})$ and gradient between acetonitril and phosphoric acid $1 \%$ solution in 20 minutes. The validation results showed that the method had good specificity, linear calibration curve in the range of $0.42-42 \mu \mathrm{g} / \mathrm{mL}$, the repeatability and recovery of the method meet the analytical requirements according to AOAC. The method has been deployed to analyze some dietary supplement products on the market and give Icariin content 6.15 - 54.3 $\mathrm{mg} / \mathrm{g}$ (in dietary supplement) and $6.47-24.5 \mathrm{~g} / 100 \mathrm{~g}$ (in powder extracts).

Keywords: Icariin, Epimedium, HPLC, dietary supplements. 